\title{
Comparative Bioavailability of Norfloxacin Tablets Based on Blood and Urine Data
}

\author{
Aly H. Nada ${ }^{a}$ Mohamed A. Sharaf ${ }^{b}$ Zeinab A. El Gholmy ${ }^{c}$ Nawal M. Khalafallah ${ }^{c}$ \\ ${ }^{a}$ Department of Pharmaceutics, Faculty of Pharmacy, Kuwait University, Kuwait; ${ }^{b}$ Alexandria Co. Pharmaceutical and \\ Chemical Industries, 'Department of Pharmaceutics, Faculty of Pharmacy, Alexandria University, Alexandria, Egypt
}

\section{Key Words}

Norfloxacin bioavailability $\cdot$ Noroxin ${ }^{\circledR} \cdot$ Bioequivalence

\begin{abstract}
Objective: To assess the bioavailability of norfloxacin from urinary excretion relative to plasma concentration. Materials and Methods: Twelve healthy volunteers (22-33 years) participated in the study. Each received a previously developed $(\mathrm{M})$, a local $(\mathrm{L})$ and a multinational (Noroxin ${ }^{\circledR}$ ) tablet (Ref), $400 \mathrm{mg}$ each, according to a random balanced threeway crossover design on 3 different days. Blood samples were collected over a 12-hour period and urine over a 24hour period. Norfloxacin concentrations were analyzed by a validated HPLC method. Results: An initial estimate of bioequivalence of the three products was obtained using analysis of variance on transformed data and based on confidence interval calculation. Elimination pharmacokinetic parameters (half-life and renal clearance) calculated from plasma concentration and urinary excretion data (mean values, $n=36$ ) were comparable to reported values for norfloxacin. Interproduct differences in elimination parameters (mean values, $n=12$ ) were statistically insignificant ( $F$ values, ANOVA). Strong association was found between the mean of plasma concentration and urinary excretion rates for many volunteers ( $F$ values, regression analysis). Relative bioavailability values calculated for the local and previously developed products relative to Noroxin were higher than $85 \%$ based on area under the curve and urinary excretion. Bio-
\end{abstract}

equivalence could not be established among the three tested products based on calculated $90 \%$ confidence intervals. Conclusion: Urinary excretion of norfloxacin may be a useful noninvasive tool for bioavailability assessment of norfloxacin oral formulations.

Copyright $\odot 2007$ S. Karger AG, Basel

\section{Introduction}

Fluoroquinolones are widely used for treatment of many urinary tract infections. About $30-40 \%$ of an oral dose of norfloxacin is absorbed in the fasting state. $\mathrm{Ab}$ sorption is rapid following a single dose of 200, 400 and $800 \mathrm{mg}$. At these doses, mean peak plasma concentrations of $0.8,1.5$ and $2.4 \mu \mathrm{g} / \mathrm{ml}$, respectively, are attained approximately $1 \mathrm{~h}$ after dosing. The presence of food may decrease absorption. The plasma half-life is $3-4 \mathrm{~h}$ and may be prolonged in renal impairment. Norfloxacin is eliminated through metabolism, biliary excretion and renal excretion. About $30 \%$ of a dose is excreted unchanged in urine within $24 \mathrm{~h}$. Some metabolism occurs possibly in the liver [1-3].

In a previous study [4], we have reported on the preparation of four norfloxacin tablet formulations (400 mg). The developed $M$ tablets showed superior in vitro characteristics and dissolution rate conforming to USP 25 standards [5] and therefore were chosen for the in vivo study.

\section{KARGER}

Fax +4161306 1234 E-Mail karger@karger.ch www.karger.com

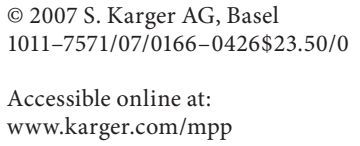

Dr. Aly H. Nada

Department of Pharmaceutics

Faculty of Pharmacy, Kuwait University

PO Box 24923, Safat 13110 (Kuwait)

Tel. +965 498 6072, Fax +965 498 6843, E-Mail alynada@hsc.edu.kw 
The aim of this study was to evaluate the bioavailability of the developed M tablets compared to a locally produced norfloxacin tablet brand (L) and the original commercially available product $\left(\right.$ Noroxin $\left.^{\circledR}\right)$ in healthy volunteers. In addition, and based on the reported extent of urinary excretion of unchanged norfloxacin, it was decided to collect both plasma and urine samples. Correlation between urinary excretion and plasma concentration data was investigated. The feasibility of using urinary excretion data to investigate norfloxacin bioavailability was explored and further to assess variance of bioavailability parameter, area under the curve (AUC), for the innovator product that could be used to obtain an estimate of the number of volunteers required for future bioequivalence studies of norfloxacin.

\section{Materials and Methods}

\section{Products and Methods}

Previously, we reported the preparation of four norfloxacin tablet formulations (400 mg), using two commercial norfloxacin raw materials and a third one developed by pregranulation with PVP/ethanol [4]. Briefly, tablets were film coated with 5\% solution of HPMC or Eudragit ${ }^{\circledR}$ E-100 in isopropyl alcohol, and their physical and chemical stability were assessed. The $\mathrm{M}$ tablets were prepared by direct compression of the developed norfloxacin raw material, employing the following additives: Avicel ${ }^{\circledR} \mathrm{PH} 102$, Aerosil ${ }^{\circledR}$, Ac-Di-Sol ${ }^{\circledR}$, lactose monohydrate, talc, and magnesium stearate. Subsequently, the tablets were protected from moisture uptake by a nonenteric coat of Eudragit E-100. Based on the observed in vitro data, the $\mathrm{M}$ tablets have been chosen for further in vivo evaluation [4].

In the present study, the bioavailability and pharmacokinetics of three tablet products, each containing $400 \mathrm{mg}$ of norfloxacin, were assessed: (a) freshly prepared $\mathrm{M}$ tablets described above; (b) a locally produced tablet brand (L); and (c) the innovator product (Ref), Noroxin tablets (batch No HA43590; Merck, Sharp \& Dohme B.V., Haarlem, Netherlands). Both L and Ref were tested within their shelf life.

All chemicals used were of analytical and HPLC grade. An HPLC method described by Pauliukonis et al. [6], was validated and applied for plasma and urine sample analysis. All HPLC equipment was from Millipore Corp., Waters Chromatography Division, Milford, Mass., USA. The same HPLC method was used for evaluation of drug content of fresh and aged tablets as well as in dissolution study of the tested formulations [4].

\section{Study Design and Analysis}

The study was conducted with the participation of 12 healthy young adult male volunteers (22-33 years, weighing $57-86 \mathrm{~kg}$ ), according to a random balanced three-way crossover design with 1-week washout period between each 2 study days (3 study days with 2 washout weeks). Informed and signed consent, and approval of the Faculty's Ethics Committee were obtained. Each volunteer took the three preparations on 3 separate study days (12 volunteers per preparation). The volunteers were included on the basis of acceptable medical histories and in good health as judged by physical examination and clinical biochemical tests. The volunteers were instructed to abstain from taking any other medication on the 3 study days and during the washout weeks and 1 week before starting the study. The dose administered with a glass of water after fasting overnight, was one 400-mg norfloxacin tablet of the M, L and Ref products. The volunteers continued fasting for $4 \mathrm{~h}$ after which a standard meal $(250 \mathrm{~g}$ grilled meat; 2 slices of bread; 1 orange; and $250 \mathrm{ml}$ drinking water) was served. Blood samples were collected in heparinized tubes at zero time (before swallowing the tablets) and at 1, 2, 3, 4, 6, 8 and $12 \mathrm{~h}$. Plasma was separated and frozen. Urine was collected at 0, 1, 2, 3, 4, 6, 812 and $24 \mathrm{~h}$, and samples were frozen. The procedure of Pauliukonis et al. [6] was adopted for preparation and analysis of plasma and urine samples. Standards in plasma $(0.5-2 \mu \mathrm{g} / \mathrm{ml})$ and blanks were prepared and processed with the plasma samples. Similarly, standards in urine $(20-80 \mu \mathrm{g} / \mathrm{ml})$ and blanks were prepared and processed with the corresponding samples. At least three recovered standards were injected on each day of analysis among the samples analyzed. Peak areas were measured.

Assay recovery and interday precision data were generated from standards assayed on different days following USP guidelines [5].

Based on the variance of the AUC for the reference product obtained in the present study, the required number of volunteers for a future bioequivalence study to detect a difference of 0.2 between norfloxacin products was calculated.

\section{Pharmacokinetic Data Analysis}

The following pharmacokinetic parameters were recorded or calculated from plasma norfloxacin concentrations and urinary excretion data: $\mathrm{C}_{\max }$ (recorded); $\mathrm{T}_{\max }$ (recorded); $\mathrm{K}_{\mathrm{el}}$ (calculated from plasma concentration); $\mathrm{t}_{1 / 2}$ (calculated); $\mathrm{AUC}_{0-12 \mathrm{~h}}$ and $\mathrm{AUC}_{0-\infty}$ (calculated by the linear trapezoidal method and extrapolating to include tail area); cumulative 24-hour excretion in urine (calculated); urinary excretion rate (calculated from cumulative amount excreted and recorded at midpoint of time period), renal clearance (calculated by dividing the 12-hour cumulative amount excreted in urine by the plasma $\mathrm{AUC}_{0-12 \mathrm{~h}}$ ). A computer program STRIPE [7] was used to generate some of these pharmacokinetic parameters.

Elimination pharmacokinetic parameters $\left(\mathrm{K}_{\mathrm{el}}, \mathrm{t}_{1 / 2}\right.$ and renal clearance) calculated from each of the three treatment data were compared using two-way analysis of variance (ANOVA).

Association between mean plasma concentrations ( $\mathrm{n}=12$ per product) at different times (1, 2, 3, 4, 6, 8 and $12 \mathrm{~h}$ ) and mean urinary excretion rates (at mid-times at 1, 2, 3, 4, 6, 8, 12 and $24 \mathrm{~h}$ ) was evaluated using regression analysis. Pharmacokinetic parameters $\left(\mathrm{AUC}_{0-12}, \mathrm{AUC}_{0-\infty}, \mathrm{C}_{\max }\right.$, and cumulative amount excreted over $24 \mathrm{~h}$ ) generated for the three treatments were compared for significant differences due to dosing days (period effect), sequence (carryover effect), subjects within sequence, and formulation using ANOVA and $90 \%$ confidence intervals.

ANOVA was performed on transformed data $\left(\mathrm{AUC}_{0-12 \mathrm{~h}}, \mathrm{C}_{\max }\right.$ and 24-hour cumulative urinary excretion) and $90 \%$ confidence intervals were calculated for parameter ratios according to USP recommendations to give an initial estimate of bioequivalence of the three products. 


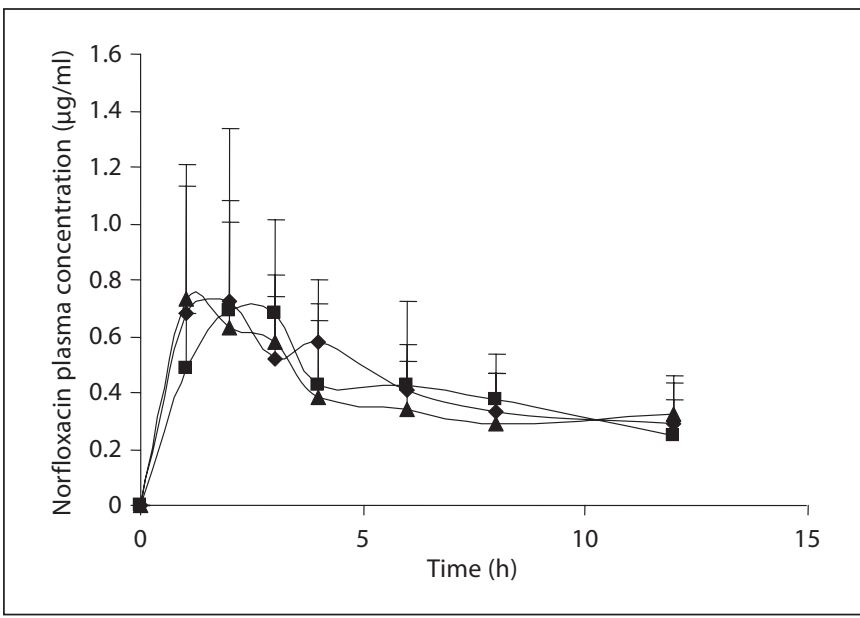

Fig. 1. Mean plasma norfloxacin concentrations following administration of $400-\mathrm{mg}$ norfloxacin tablets to 12 volunteers. $\downarrow=$ Ref; $\mathbf{\square}=\mathrm{L} ; \boldsymbol{\Delta}=\mathrm{M}$.

\section{Results}

The potency of tested tablets (\% of labeled claim) was 102.16, 94.77 and $92.88 \%$ for Ref, L and M, respectively. All tablets passed USP 25 dissolution limit for norfloxacin tablets (not less than $80 \%$ dissolution in $30 \mathrm{~min}$ ). Methodology for drug content and dissolution rate has previously been detailed [4]. No correction for potency differences was applied to in vitro or in vivo results obtained in the present study.

The assay recovery was $50.57 \%$ for plasma standards $0.5-2.0 \mu \mathrm{g} / \mathrm{ml}$ (values ranged from $64.30 \pm 12.74 \%$ at 0.5 $\mu \mathrm{g} / \mathrm{ml}$ to $49.18 \pm 15.18 \%$ at $2.0 \mu \mathrm{g} / \mathrm{ml})$ and $32.51 \%$ for urine standards $20-80 \mu \mathrm{g} / \mathrm{ml}$ (values ranged from 31.46 $\pm 12.55 \%$ at $20 \mu \mathrm{g} / \mathrm{ml}$ to $30.39 \pm 10.67 \%$ at $80 \mu \mathrm{g} / \mathrm{ml}$ ). Coefficients of variation values for interday precision were below $10 \%$ for plasma standards and below $15 \%$ for urine standards. The limit of quantitation for the determination of norfloxacin in plasma was 0.02 and $0.8 \mu \mathrm{g} /$ $\mathrm{ml}$ for the urine samples. Mean plasma levels are plotted in figure 1, showing double peak phenomenon.

Mean urinary excretion rates are plotted in figure 2. Cumulative urinary excretion data obtained for each volunteer (at 1, 2, 3, 4, 6, 8, 12, and $24 \mathrm{~h}$ ) allowed calculation of excretion rates $(\mathrm{mg} / \mathrm{h})$ corresponding to mid-times (at $0.5,1,1.5,2$, up to $18 \mathrm{~h}$, fig. 2 ).

Percent bioavailability values for products $\mathrm{L}$ and $\mathrm{M}$ compared to Ref calculated from $\mathrm{AUC}_{0-12 \mathrm{~h}}, \mathrm{AUC}_{0-\infty}$ and 24-hour cumulative urinary excretion are shown in table 1. Percentage extrapolation of area accounted for

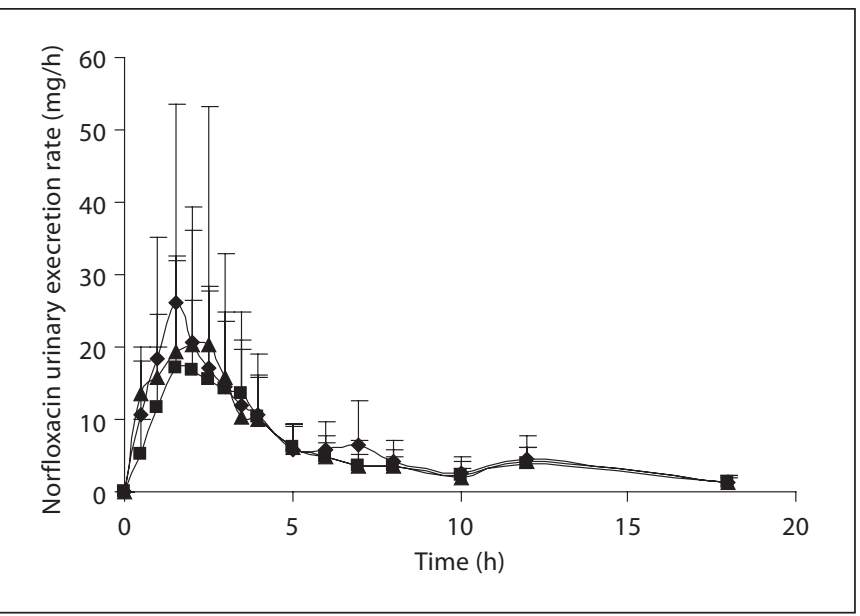

Fig. 2. Mean urinary excretion rate profiles following administration of 400-mg norfloxacin tablets to 12 volunteers. $\boldsymbol{\nabla}=$ Ref; $\mathbf{\square}=$ $\mathrm{L} ; \boldsymbol{\Delta}=\mathrm{M}$.

26.97, 29.72 and $31.55 \%$ of mean $\mathrm{AUC}_{0-\infty}$ for Ref, $\mathrm{L}$ and $\mathrm{M}$, respectively (calculated from table 1). Percent bioavailability values obtained for $M$ ranged from 85.50 to 92.13 depending on the parameter used in the calculation. Bioavailability values calculated from urinary excretion were higher for $\mathrm{M}$ and lower for $\mathrm{L}$ compared to corresponding values calculated from AUC.

$\mathrm{T}_{\max }$ values corresponding to maximum urinary excretion rate were slightly lower than corresponding $\mathrm{T}_{\max }$ values obtained from plasma profiles.

Mean elimination pharmacokinetic parameters calculated from plasma concentration and urinary excretion data were as follows: $K_{\mathrm{el}} 0.199 \mathrm{~h}^{-1}$ (士SEM 0.022), renal clearance $334.96 \mathrm{ml} / \mathrm{min}$ ( \pm SEM 29.86), $\mathrm{t}_{1 / 2} 5.66 \mathrm{~h}$ ( \pm SEM 0.814), and 24-hour urinary excretion 103.727 mg ( \pm SEM 9.214).

Differences between the three products in $\mathrm{K}_{\mathrm{el}}$ and renal clearance values obtained in the present study were statistically insignificant (ANOVA results; table 2), which validates assessment of comparative bioavailability based on AUC.

Strong association exists between the mean plasma concentrations and mean urinary excretion rates for the three products. Correlation coefficient for pooled mean data (21 pairs of data) was 0.915 ( $\mathrm{p}<0.01)$. Estimated correlation coefficient $(r)$ values of mean plasma concentration at different times and corresponding mid-times mean urinary excretion rate for the norfloxacin products Ref, L and M (7 pairs of data each) were 0.947, 0.906, and 0.912, respectively. Strong association between plasma 
Table 1. Mean bioavailability-indicating parameters calculated from plasma concentration and urinary excretion data following the oral administration of one 400-mg norfloxacin tablet of the Ref, L and M products

\begin{tabular}{llll}
\hline Parameter $(\mathrm{n}=12)$ & Ref & $\mathrm{L}$ & $\mathrm{M}$ \\
\hline $\mathrm{AUC}_{0-12 \mathrm{~h}, \mu \mathrm{g} \cdot \mathrm{ml}^{-1} \cdot \mathrm{h}}$ & $5.030 \pm 1.375$ & $4.739 \pm 2.007$ & $4.455 \pm 2.035$ \\
Relative bioavailability based on $\mathrm{AUC}_{0-12 \mathrm{~h}}$ & - & $94.21 \%$ & $88.57 \%$ \\
$\mathrm{AUC}_{0-\infty}, \mu \mathrm{g} \cdot \mathrm{ml}^{-1} \cdot \mathrm{h}$ & $6.888 \pm 1.954$ & $6.514 \pm 2.200$ & $5.889 \pm 3.161$ \\
Relative bioavailability based on $\mathrm{AUC}_{0-\infty}$ & - & $94.57 \%$ & $85.50 \%$ \\
Tail area, $\mu \mathrm{g} \cdot \mathrm{ml}^{-1} \cdot \mathrm{h}$ & $1.858 \pm 1.152$ & $1.936 \pm 1.676$ & $1.858 \pm 1.132$ \\
24-hour cumulative excretion, mg & $112.070 \pm 71.724$ & $95.864 \pm 50.623$ & $103.248 \pm 43.281$ \\
Relative bioavailability based on & & & $92.13 \%$ \\
$\quad$ 24-hour urinary excretion & - & $85.54 \%$ & $0.856 \pm 0.408$ \\
$\mathrm{C}_{\text {max }}, \mu \mathrm{g} \cdot \mathrm{ml}^{-1}$ & $0.964 \pm 0.362$ & $0.937 \pm 0.528$ & $1.75 \pm 0.87$ \\
$\mathrm{~T}_{\max }, \mathrm{h}($ from plasma data) & $2.08 \pm 1.24$ & $2.17 \pm 0.83$ & $1.58 \pm 0.79$ \\
$\mathrm{~T}_{\max }, \mathrm{h}($ at maximum urinary excretion rate) & $1.92 \pm 0.79$ & $1.75 \pm 0.75$ & \\
\hline
\end{tabular}

Table 2. Two-way ANOVA applied to elimination pharmacokinetic parameters calculated for each product (mean \pm SEM)

\begin{tabular}{|c|c|c|c|c|c|}
\hline Parameter $(\mathrm{n}=12)$ & Ref & $\mathrm{L}$ & M & $\begin{array}{l}\text { F value } \\
\text { between products }\end{array}$ & $\begin{array}{l}\text { F value } \\
\text { between subjects }\end{array}$ \\
\hline $\mathrm{K}_{\mathrm{el}}, \mathrm{h}^{-1}$ & $0.195 \pm 0.028$ & $0.217 \pm 0.049$ & $0.184 \pm 0.037$ & $0.166, \mathrm{NS}^{1}$ & $0.850, \mathrm{NS}^{2}$ \\
\hline Renal clearance, $\mathrm{ml} / \mathrm{min}$ & $342.56 \pm 74.76$ & $290.90 \pm 31.61$ & $371.42 \pm 40.22$ & $0.781, \mathrm{NS}^{1}$ & $1.853, \mathrm{NS}^{2}$ \\
\hline
\end{tabular}

NS $=$ Not significant. ${ }^{1}$ Critical F at 0.05 , d.f. $(2,22)$ is $3.443 .{ }^{2}$ Critical F at 0.05 , d.f. $(11,22)$ is 2.3 .

concentration and urinary excretion rate could not be demonstrated for each individual volunteer data and of 36 correlations attempted, 13 of them were highly correlated $(\mathrm{p}<0.05)$.

ANOVA applied to the $\log \mathrm{AUC}_{0-12 \mathrm{~h}}$ values calculated for the three tablets is shown in table 3. Furthermore, the $90 \%$ confidence intervals for $\log \mathrm{AUC}_{0-12 \mathrm{~h}}, \log \mathrm{C}_{\max }$ and $\log 24$-hour urinary excretion of the three products are presented in table 4.

The coefficient of variation for reference product $\mathrm{AUC}_{0-12 \mathrm{~h}}$ was 0.2736 and for $\mathrm{AUC}_{0-\infty}$ it was 0.2837 (SD/ mean, calculated from table 1) and yielded an estimate of 30-32 volunteers, respectively. The equation used was $\mathrm{n}=15.68 \times$ variance of Ref/0.04 [8].

Based on calculated $\mathrm{F}$ values for $\log \mathrm{AUC}_{0-12 \mathrm{~h}}$ data (table 3), sequence effect proved insignificant, $F$ value for period effect was statistically significant and $F$ value for treatment effect was low and statistically insignificant. Similar $\mathrm{F}$ values and their significance were obtained with $\log \mathrm{C}_{\max }$ and $\log 24$-hour urinary excretion (results not shown). F value for subjects within sequence was significant only for $\log \mathrm{C}_{\max }$.
Table 3. ANOVA applied to $\log \mathrm{AUC}_{0-12 \mathrm{~h}}$ data generated following oral administration of one 400-mg norfloxacin tablet of the Ref, $\mathrm{L}$ and $\mathrm{M}$ products

\begin{tabular}{lclll}
\hline Parameter & d.f. & $\begin{array}{l}\text { Sum of } \\
\text { squares }\end{array}$ & $\begin{array}{l}\text { Mean of } \\
\text { squares }\end{array}$ & $\mathrm{F}$ \\
\hline $\begin{array}{l}\text { Sequence } \\
\text { Subjects within }\end{array}$ & 2 & 0.0350 & 0.0175 & $0.561, \mathrm{NS}$ \\
$\quad$ sequence & 9 & 0.2810 & 0.0312 & $1.209, \mathrm{NS}$ \\
$\begin{array}{l}\text { Period } \\
\text { Treatment }\end{array}$ & 2 & 0.353 & 0.177 & $6.841, \mathrm{p}<0.05$ \\
Error & 2 & 0.067 & 0.033 & $1.271, \mathrm{NS}$ \\
\hline Total & 20 & 0.517 & 0.026 & \\
& 35 & 1.250 & & \\
\hline
\end{tabular}

Calculated 90\% confidence intervals were outside the predefined range of $0.8-1.25$ (table 4). Under the conditions of the present study, and based on confidence intervals calculated, bioequivalence of the three products could not be demonstrated. 
Table 4. $90 \%$ confidence intervals

\begin{tabular}{llll}
\hline Parameter & Treatments & $\begin{array}{l}\text { Geometric } \\
\text { mean ratio }\end{array}$ & 90\% CI \\
\hline Log $\mathrm{AUC}_{0-12 \mathrm{~h}}$ & L/Ref & 0.897 & $0.70-1.17$ \\
$\log \mathrm{C}_{\max }$ & M/Ref & 0.815 & $0.64-1.04$ \\
$\log 24$-hour urinary & M/Ref & 1.099 & $0.77-1.56$ \\
$\quad$ excretion & M/Ref & 1.191 & $0.84-1.69$ \\
\hline
\end{tabular}

${ }^{1}$ Antilog of average difference between log parameters.

\section{Discussion}

Regarding assay recovery, Pauliukonis et al. [6] reported recovery values of $85.6 \pm 16.7 \%$ in plasma assay (double extraction) and $42.2 \pm 6.0 \%$ in urine assay (single extraction). However, these recovery values are higher than corresponding values we achieved using the same methodology.

Although M tablets showed about $94.2 \%$ relative bioavailability, calculation of relative bioavailability of $\mathrm{M}$ tablets using a correction factor taking into account the actualdrug contentrelative to thelabeled value (100/92.88) would result in mean relative bioavailability of $101.4 \%$. However, all calculations and statistics are based on the actual drug contents of all tested tablets, since they conformed to the potency specifications of USP 25 regarding norfloxacin tablets (90-110\% of claimed content). Since $\mathrm{M}$ tablet potency (92.88\%) could be partly responsible for the observed low bioavailability, this should be improved before a full bioequivalence study is undertaken for product M. Similar bioavailability results were found with product L.

The individual plasma profiles obtained showed more than one peak in some individuals probably due to enterohepatic recycling $[2,3]$, in agreement with data re-

ported for norfloxacin by Pauliukonis et al. [6] for one subject. Similarly, individual plasma profiles reported for pefloxacin, another fluoroquinolone antibacterial agent, also showed several peaks following both intravenous and oral administration [9].

Mean $\mathrm{AUC}_{0-12 \mathrm{~h}} \mathrm{~h}$ values for the three products (table 1 ) were comparable to corresponding values reported for a similar oral dose of norfloxacin $\left(\mathrm{AUC}_{0-12 \mathrm{~h}} 6.26 \pm\right.$ $2.05 \mu \mathrm{g} \cdot \mathrm{h} / \mathrm{ml}$ ) [10].

Previous reports about norfloxacin pharmacokinetics were reviewed and compared to the results of this study [11-14]. Mean values for $t_{1 / 2}$ calculated from plasma $(5.66 \mathrm{~h})$ is higher than values of 3.50 and 3.75 reported by Wise et al. [12] and Lee et al. [13], respectively, but comparable to values of 5.32 and $5.57 \mathrm{~h}$ reported by Chen et al. [14]. Also, reported values for renal clearance of norfloxacin are 285 [11], 205 and $238 \mathrm{ml} / \mathrm{min}$ [13], compared to $335 \mathrm{ml} / \mathrm{min}$ in the present study (table 2).

Values reported for percent of the dose excreted unchanged in $24 \mathrm{~h}$ include 22.5 and $28.6 \%$ for two $400-\mathrm{mg}$ tablet brands [14], and $27 \%$ in another study [12], compared to $25.93 \%$ in the present study (table 2).

$\mathrm{T}_{\max }$ corresponding to peak excretion rate occurred slightly earlier than $\mathrm{T}_{\max }$ from plasma drug levels and indicated need to modify blood sampling schedule in future bioequivalence studies for norfloxacin.

\section{Conclusion}

The developed norfloxacin tablets $\mathrm{M}$ and the local commercial product L showed comparable bioavailability to Ref formulation, based on AUC and urinary excretion; however, bioavailability values generated from the two sets of data were not identical. Strong association was established between plasma concentration and urinary excretion rates for mean but not for all individual volunteer data. Adjustment of the $\mathrm{M}$ formulation is needed before a full bioequivalence study on 30 or 32 volunteers is undertaken.
References
4 Nada AH, Sharaf MA, Elgholmy ZA, Khalafallah NM: Effect of raw materials on the formulation of norfloxacin tablets. Pharm Technol Eur 2006;18:36-45.

5 The United States Pharmacopoeia, ed 25. United States Pharmacopeial Convention, Rochville, 2002, p 1250.
Press, London, 2004, p 239.

3 PDR Generics, ed 3. Medical Economics, Montvale, 1997. ones in the treatment of serious bacterial urinary tract infections. Drugs 2004;64: 1359-1373.

2 Sweetman SC (ed): Martindale, The Complete Drug Reference, ed 34. Pharmaceutical 
6 Pauliukonis LT, Musson DG, Bayne WF: Quantitation of norfloxacin, a new antibacterial agent in human plasma and urine by ion-pair reverse phase chromatography. J Pharm Sci 1984;73:99-102.

7 Johnston A, Woollard RC: STRIPE: an interactive computer program for the analysis of drug pharmacokinetics. J Pharmacol Methods 1983;9:193-199.

-8 Marzo A, Balant LP: Bioequivalence. Updated reappraisal addressed to applications of interchangeable multi-source pharmaceutical products. Arzneimittelforschung 1995; 45:109-115.
9 Barre J, Houin G, Tillement JP: Dose-dependent pharmacokinetic study of pefloxacin, a new antibacterial agent, in humans. J Pharm Sci 1984;73:1379-1382.

-10 Swanson BN, Boppana VK, Vlasses PH, Rotmensch HH, Ferguson RK: Norfloxacin disposition after sequentially increasing oral doses. Antimicrob Agents Chemother 1983; 23:284-288.

11 Adhami ZN, Wise R, Weston D, Crump B: The pharmacokinetics and tissue penetration of norfloxacin. J Antimicrob Chemother 1984;13:87-92.
12 Wise R, Lister D, McNulty CA, Griggs D, Andrews JM: The comparative pharmacokinetics and tissue penetration of four quinolones including intravenously administered enoxacin. Infection 1986;14:S196-S202.

13 Lee SF, Wang RB, Lin MF: Comparative bioavailability and pharmacokinetics of norfloxacin. Zhonghua Yaoxue Zazhi 1992;44: 413-420.

14 Chen X, Liu X, Huang S, Wang F: Pharmacokinetics of norfloxacin by constant rate infusion. Zhongguo Linchuang Yaoli Zazhi 1992; 8:82-86. 